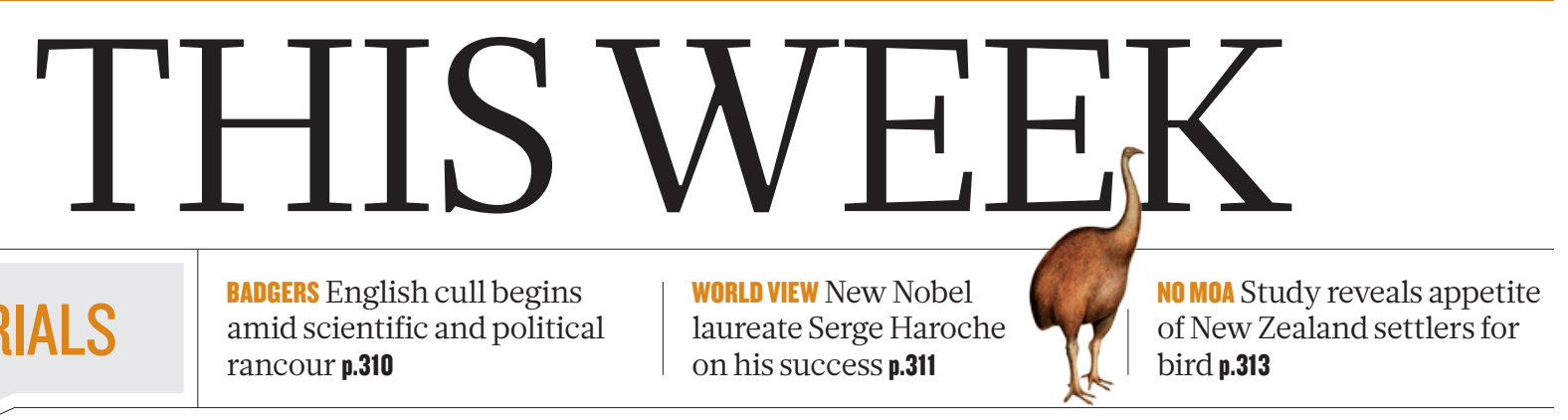

EDITORIALS amid scientific and political rancour $\mathbf{p . 3 1 0}$

\title{
Life after death
}

\section{Restricting access to US death records could have serious consequences for long-term health studies. Government agencies should rethink their decision.}

$\mathrm{P}$ eople who receive kidney transplants live twice as long as those who rely on dialysis. Trans fats are bad for your health. High alcohol consumption is linked with increased rates of breast cancer. High caffeine consumption is not. Daily aspirin use is associated with a reduced risk of death from cancer.

Large and long-term population studies have revealed these and other important findings. All required access to death records, which a policy from the US Social Security Administration (SSA) is making more difficult and more expensive.

The SSA produces the Death Master File, or Social Security Death Index, which includes more than 89 million records and lists names, death dates and social-security numbers. Data come from state governments, postal authorities, financial institutions, relatives of the deceased, health-care providers and funeral homes, and are updated weekly; the file has been publicly available since 1980. Last November, however, the SSA stopped making state death data generally available, saying that such information is protected by privacy laws.

Some 4 million entries have been removed from the public file because of privacy concerns. In future, an estimated 1 million of the 2.8 million records collected each year by the SSA will no longer be made public. That will make it much harder for researchers to track down whether a participant in a study has moved or died. It could also prevent researchers from collecting accurate details about circumstances of death while the memories of relatives and health providers are fresh.

Researchers involved in US longitudinal and cohort studies such as the Nurses' Health Study and the Framingham Heart Study routinely consult the Death Master File, as do those at the Scientific Registry of Transplant Recipients. It was used to verify deaths in the Cancer Prevention Study II, and so has contributed to more than 200 published studies from the American Cancer Society. Health networks and funders must know who has died so that they can evaluate quality of care, the longterm benefits of a procedure or the risks of an intervention.

But fraudsters also have uses for death records: criminals can use the listed social-security numbers for identify theft. However, the benefits of restricting access to the database to curtail fraud must be weighed carefully against the real potential for harm to public health. Without access to death records, research in all areas of medicine will be hindered. Ironically, efforts to prevent other kinds of fraud will also be obstructed, because the records can be used to check whether the holder of a social-security number has died.

There are other sources of death records. Investigators can submit the names of study participants to the Centers for Disease Control and Prevention (CDC), which will then search its National Death Index for matches in data supplied by the states. This index is more complete than the Death Master File, but it is updated less frequently — only every 18 months or so. It is also less convenient to use, and more costly. The CDC must pay states for their records, and these costs are passed on to researchers. The agency is working closely with state offices to

adopt electronic filing systems that can keep lists more current, but the costs are unlikely to come down.

Even studies that already rely on the CDC still use the Death Master File for corroboration and extra information. Without access to this resource, researchers will need to spend further research dollars and effort on tracking down participants. They may have to send expensive signed-for letters to ensure that they reach someone, or chase through defunct contact information. The quality of studies will suffer. The

"There is a lot of room between making data accessible indiscriminately and cutting off access." more participants are lost to follow-up, the less certain will be the conclusions of longstanding, labour-intensive cohort studies.

The SSA should reconsider its decision to withhold information. Everyone involved should work to find a compromise that minimizes the risks of identify theft while maintaining researchers' access to all the data in the Death Master File.

Before the latest policy took effect, nearly anyone could gain access to the records. Genealogy sites posted data for free or at minimal cost, and it is true that these records were easy pickings for identity thieves. However, there is a lot of room between making data accessible indiscriminately and cutting off access. The medical community is accustomed to working with sensitive, confidential information. To give accredited researchers access to death records, the SSA could adopt registration and permissions systems similar to those used for viewing and receiving medical information.

Given how many federal dollars will be wasted if access to the Death Master File is restricted - and how many public-health benefits will be lost or delayed - officials must work urgently to make these crucial records available for research once again.

\section{Global reach}

\section{The increasing internationalization of science offers many benefits, but also has limitations.}

$\mathrm{L}$ ast week's Nobel prizes formally recognized scientists from just four nations - but newspaper headlines and press releases were leager to spread the glory further. Whereas France's President François Hollande called Serge Haroche's physics win "a source of national pride", Helga Nowotny, president of the European Research Council, described the same award as affirmation of her agency's investment in talent.

The Korea Herald, meanwhile, found a local connection to US 
researcher Robert Lefkowitz's chemistry Nobel — two Korean scientists, Jihee Kim and Seungkirl Ahn, are currently working in his lab.

And although Japan's Shinya Yamanaka was personally congratulated by Prime Minister Yoshihiko Noda on his award in physiology or medicine, the San Jose Mercury News preferred to focus on Yamanaka's training at the Gladstone Institutes in San Francisco, California, which, the paper said, recognized his talents back in 1993 , when they hired him (Yamanaka still has a lab there).

Reactions such as these show how national pride and prestige still matter in an increasingly internationalized science system. The ultimate expression of that tension will surely come when the discovery of the Higgs boson - to which thousands of researchers and funds from tens of countries contributed - is rewarded with a call from Stockholm.

This week, Nature examines the globalization of science (see page 325). According to the US National Science Foundation (NSF), almost one-quarter of research articles in 2010 featured authors from more than one country, up from $10 \%$ in 1990 . The average number of authors on research papers, which now stands at 4.5 , has doubled since 1980. Many areas of science are becoming international, not local, pursuits; researchers are increasingly criss-crossing the globe and becoming accustomed to working in two or three countries at once.

Yet although science is increasingly globalized - at least in terms of research outputs and collaborations - it is still funded and managed on a largely national basis. This may need to change. Joining up national priorities could allow economies of scale, possibly to the benefit of research into global challenges such as energy, climate and agriculture.
The head of the NSF, Subra Suresh, offers a vision of the future on page 337 in which some of the barriers to cross-border scientific collaboration have been removed. Suresh hopes that the Global Research Council can begin to collectively steward global science as if it were a national activity.

If the globalizing trend does continue, it could change the way that national governments view the outputs of science. Countries may even
"Joining upnational priorities could allow economies of scale." feel that, instead of insisting on making and exploiting their own discoveries, it is more efficient to capitalize on the breakthroughs made by others. South Korea and the United States are rapidly becoming the centres of graphene manufacturing, for instance, despite the 2010 physics Nobel being awarded to graphene researchers at the University of Manchester, UK.

Yet there are limits to internationalization. Mobility cannot stretch infinitely: relationships, families and quality of life put limits on how much researchers want to travel, and for how long. Meanwhile, some national research systems, such as that of Japan, are not particularly flexible and discourage scientists from spending too much time abroad.

And blurring the borders of national priorities may not be all good. Some countries are just beginning to build their own research capacity. Collaboration may allow them to share in the advances of others, but it could also start to dilute their national identity, subjugating local research priorities to the interests of larger nations. Striking the balance between local and global science will be the challenge.

\section{Badger away}

\section{Charges that the UK badger-shooting policy ignores evidence are wide of the mark.}

\section{$\mathrm{I}$} n England's meadows, a massacre is imminent. As Nature went to press, licensed marksmen were getting ready to take aim at badgers - a native species that is a known carrier of bovine tuberculosis (TB). By the time you read this, the first shots in a long and bloody conflict may have been fired.

Scientists are outraged. Many researchers insist that the government has ignored the data in favour of a policy to appease farmers. But the evidence suggests something else: politicians have reviewed the science and have responded to it. The resulting policy is far from what many scientists would have hoped, but it is nevertheless based on evidence.

As described on page 317, the badger question is one of the moststudied environmental problems in modern Britain. At issue is the degree to which badgers (Meles meles) contribute to the spread of bovine TB - an economically costly disease - and whether killing them can help to control it. Decades of study have led to a clear scientific answer of "a fair bit" to the first question and "maybe" to the second.

More specifically, an extensive, randomized study showed a roughly $23 \%$ reduction in bovine TB over a 9 -year period of badger culling in small areas. The same study, however, concluded that catching the badgers in cages and shooting them was unlikely to be economically practical and therefore advised against it.

On the basis of that evidence, the previous, Labour government decided not to instigate a badger cull. The present Conservative-led government sees things differently. With a cheaper cull strategy that relies on free shooting instead of traps, the government believes badger culling might help to reduce bovine TB, which has been rising steadily.

Scientists have not been excluded from this decision. In April 2011, the Department for Environment, Food and Rural Affairs convened a panel of scientists to review the evidence and advise on whether a cull could work. The scientists, including several who now actively oppose the government's policy, gave a qualified 'yes'. Culling could reduce bovine TB by perhaps $16 \%$ over 9 years, the scientists said, but it would be difficult to know if free shooting would work because it differed from the method tested in the previous trial.

Partly on the basis of that analysis, the government seems to think that it's worth a shot. In combination with other techniques, such as increased monitoring and controls on cattle movements, it hopes that the badger cull can bring bovine TB under control. The politicians accept the modest reduction that scientists say the cull may bring, and have adopted scientific recommendations for how best to implement it, such as using rivers and roads as boundaries for their cull areas and setting a 70\% target for the number of badgers killed (although knowing when this target has been reached will be difficult, because there has been no census of badger populations).

Scientists protest that this decision is still unscientific, because the methods to be used are too different from those of the original trial and because the evidence suggests that they may not work. There is a chance that the cull will have little impact or could even increase the TB rate if improperly conducted.

But it is the government's job to create and implement policy, not to perform science experiments. Politicians must make decisions every day with imperfect knowledge, knowing that many of those choices may turn out to be ineffective. In this case, they feel a need to do something to bring bovine TB under control - or at least to be seen to be trying to do so. They also face considerable pressure from unhappy farmers who are being told to implement costly biosecurity measures while badgers run free.

Politicians all too frequently ignore scientific evidence, or worse still, distort it for their own purposes. The political debates over genetically modified food in Europe and climate change in the United States in recent years hold many examples of such behaviour. The badger issue is more nuanced. Politicians have understood the evidence, have $\rightarrow$ NATURE.COM To comment online, click on Editorials at: go.nature.com/xhunqv acknowledged this evidence publicly and have made a policy that partially reflects it. Scientists have every right to disagree with the conclusion, but they should reconsider their criticisms of how it was reached. 